\title{
Knowledge, Attitude, and Practice, about Digital and Conventional Radiographs among General Dentists and Specialists in Kanchipuram District
}

\author{
Divya Sanjeevi Ramakrishnan ${ }^{1}$ Sudarssan Subramaniam Gouthaman², Senthilnathan Periasamy ${ }^{3}$ \\ 1, 2, 3 Department of Oral Surgery, Saveetha Institute of Medical and \\ Technical Sciences, Kuthambakkam, Tamil Nadu, India.
}

\section{ABSTRACT}

\section{BACKGROUND}

Radiographs are an important tool in maximizing oral health care. During initial years, the film based radiographic images were used, as technological advancements progressed, digital radiographic imaging has become an indispensable tool in diagnosis. The aim of the present study is to evaluate the practice of digital and conventional radiographs, and radiation safety among dental practitioners.

\section{METHODS}

A questionnaire descriptive study was conducted, including general dental practitioners and dental specialists in Kanchipuram district. The questionnaire comprised of 12 questions that were distributed through Google forms, email and responses were collected. The questions were based on their preference about digital or conventional radiographs, reason for their preference, satisfaction with diagnostic quality, patient compliance, and their radiation protection practice.

\section{RESULTS}

A total of 200 dental practitioners in Kanchipuram district was given questionnaires. All of them answered the questionnaire. 148 were males and 52 were females. The age distribution was between 26 - 33 years. $65 \%$ of the practitioners answered that they use digital radiographs often owing to less time consumption and ease of storage, $90 \%$ of them answered that their diagnostic quality is improved by using digital radiographs, of which $51 \%$ use radiation protection and $39 \%$ of their patients use radiation protection during exposure.

\section{CONCLUSIONS}

This era is moving towards digital radiography, among the ones who are using it, most of them are satisfied with it. Attitude towards radiation protection and hazards has to be improved amongst dental practitioners. The use of digital radiography is increasing among dental practitioners due to its less radiation exposure, improved diagnostic quality, ease of access and as it is less time consuming. The need for availability of standard improved quality of care equally raises the point for cost effective methods for the developing technologies.

\section{KEY WORDS}

Digital Radiography, Conventional Radiography, Dental Practitioners, Comparison, Awareness
Corresponding Author: Dr. Divya Sanjeevi Ramakrishnan, B1, 143 Kendhriya Vihar Apartments, Velapanchavadi - 600077, Chennai, Tamil Nadu, India.

E-mail: divyaramakrishnan55@gmail.com

DOI: $10.14260 /$ jemds/2020/702

How to Cite This Article:

Ramakrishnan DS, Gouthaman SS, Periasamy S. Knowledge, attitude, and practice about digital and conventional radiographs among general dentists and specialists in Kanchipuram district. J Evolution Med Dent Sci 2020;9(43):32003203, DOI: 10.14260/jemds/2020/702

Submission 22-06-2020,

Peer Review 19-09-2020,

Acceptance 25-09-2020,

Published 26-10-2020.

Copyright (C) 2020 Divya Sanjeevi Ramakrishnan et al. This is an open access article distributed under Creative Commons Attribution License [Attribution 4.0 International (CC BY 4.0)] 


\section{BACKGROUND}

Radiographs play a vital role in the diagnosis, treatment planning, and follow-up of oral and maxillofacial disorders. Over the course of time, various substantial changes were made in radiographic imaging modalities. Digital radiography was introduced in the mid-1980s by Francis Mouyen. Due to consistent growth in digital imaging in recent years, it is now replacing the conventional radiography in all aspects.

Conventional radiography as a whole consists of cycles of process such as image acquisition, chemical processing, transportation, storage and image display. However, equipment such as cathode-ray tubes for image display, special sensors for image acquisition, and storage devices for image archiving has become more specialized. Thus, key to its success lies in the independent performance of these functions.

New generation technologies and their evolution over the years, facilitated to acquire and display digital radiographic images. ${ }^{1}$ It has been proved that digital imaging systems have many effective advantages over conventional imaging system.23,4 One of the major advantages is the contrast and density modulations to improve the overall diagnostic imaging quality. ${ }^{5}$ It also helps in dispensing the information among other practitioners and easier to explain to patients by viewing an image on a monitor. A study in 2010 indicates that digital radiograph is a global trend that is considerably thriving due to the rapid evolution of digital technology. ${ }^{6}$

Digital radiography has been available in dentistry for more than 25 years, but digital imaging has not replaced conventional film-based radiography completely. When any new technique such as digital radiography is practiced, usually acquiring the working knowledge about it takes time. The quality of the digital imaging system to control is complicated, as the defining variables are entirely contemporary than conventional imaging systems.

Depending on a type of the sensor for image capturing, the digital radiography can be divided into 2 categories: (1) direct digital systems; and (2) indirect digital systems. Silicon devices like Complementary Metal Oxide Semiconductor (CMOS) or Charge Coupled Devices (CCD) are a direct digital system. CMOS or CCD sensors are also known as solid-state detectors. Storage Phosphor Plates (SPP), also referred as Photo Stimulable Phosphor Plates (PSP) are example of indirect digital system. ${ }^{7}$

Digital panoramic radiography usually exposes a low dose radiation than conventional radiography. ${ }^{8}$ The effects of the $\mathrm{X}$ ray on the living tissue are quite harmful and lethal which could lead to serious complications, ${ }^{9}$ therefore, it is very pertinent to understand the potential risks and preventive measures accurately.

Although digital radiography is getting increasingly popular, there are various imaging parameters that play a role in diagnostic quality. The aim of the present study is to evaluate the practice and awareness of digital and conventional radiographs among general dentists and specialists in Kanchipuram district.

\section{METHODS}

A questionnaire descriptive study consisting of 12 questions was conducted among 200 dental practitioners of which all of them answered; among them 148 were male and 52 were female. The questionnaire is distributed among the practitioners via email. The questionnaire was self-prepared containing 12 questions. For content validation of these questions, a pilot survey was done with ten dental practitioners. All the contents of questionnaire along with multiple options are checked by the experts and reliability was $100 \%$. Validated questionnaire result is $80 \%$ for this study.

The questionnaire was divided into a number of sections. The first information on participants' socio-demographic and practice characteristics. They had been asked whether they used digital radiography. The questionnaire consists of reasons for preferring digital radiographs, reasons for preferring conventional radiographs, quality, patient and operator compliance and about both operator and patient radiation protection practice. Informed consent before the survey was obtained from the practitioner. This investigation was approved by the Institutional Review Board and met all requirements regarding research involving human subjects, including informed consent and ethical conduct.

\section{Inclusion Criteria}

Dental practitioners in Kanchipuram district were included who were willing to participate.

\section{Exclusion Criteria}

The practitioners who were not willing to participate or not available during the survey were excluded from the study.

\section{Sample Size Calculation}

Sample size is calculated using G-power software, a prior analysis with standard error as $5 \%$ and power of the study as $95 \%$, the minimum sample size was calculated as 200 .

\section{RESULTS}

Questionnaire was distributed among 120 dental practitioners; all 120 practitioners answered the questionnaire; 48 were male and 72 were female; the age distribution was 27 - 33 years; majority of the respondents was general dental practitioners (21\%), oral surgeons (14.9 $\%)$, endodontists (13\%).

$65 \%$ of them answered that they use digital radiographs often and $48 \%$ use conventional radiograph often, $90 \%$ of them answered that their diagnostic quality is improved by using digital radiographs. $38 \%$ of them choose digital radiograph for panoramic diagnostic image, and $29 \%$ for periapical and $12 \%$ for cephalometric, $13 \%$ for CBCT and $8 \%$ of them use 3D-CT.

$24 \%$ of practitioners use digital radiograph to detect relationship of mandibular third molar to IAN (Inferior Alveolar Nerve) and $35 \%$ of them use digital radiograph to 
evaluate extent of large lesions, $12 \%$ for post-operative care and $15 \%$ for trauma.

$62 \%$ of practitioners do not use digital radiographs as they are expensive, $6 \%$ because of poor image quality, $17 \%$ because of no nearby centres for digital radiography, difficulty in operating $5 \% .32 \%$ use digital radiography as they can assess the images immediately, $26 \%$ for ease of image storage, for image adjustments $16 \%, 12 \%$ for less time consumption, as less radiation dose only $3 \%$ and for all of the above reasons $11 \%$ responses. $72 \%$ of practitioners were satisfied with the digital radiography, $76 \%$ patients of practitioners were satisfied with the digital radiography. $51 \%$ of the practitioners used radiation protection and $39 \%$ of their patients used radiation protection during exposure.

\begin{tabular}{|ccc|}
\hline Question & Answer & Response \\
\hline Designation & Endodontist & $26(13 \%)$ \\
& Periodontists & $20(10 \%)$ \\
& General Dentist & $42(21 \%)$ \\
& Oral Medicine & $24(12 \%)$ \\
& Oral Surgeon & $29(14.49$ \\
& Paedodontist & $\%)$ \\
& Orthodontist & $12(6 \%)$ \\
Type of & Prosthodontist & $21(10.5 \%)$ \\
radiographs for & A. Panoramic & $26(13 \%)$ \\
digital imaging & B. Periapical & $76(38 \%)$ \\
& C. Cephalometric & $58(29 \%)$ \\
& D. CBCT & $24(12 \%)$ \\
Why do you & E. 3D - CT & $26(13 \%)$ \\
prefer digital & A. Relationship of mandibular third molar and & $16(8 \%)$ \\
radiographs & inferior alveolar nerve canal & $48(24 \%)$ \\
& B. Evaluate the extent of large lesions & $70(35 \%)$ \\
& C. To evaluate trauma & $30(15 \%)$ \\
\hline & D. Post-operative examinations & $24(12 \%)$ \\
\hline & E. All of the above & $28(14 \%)$ \\
\hline & Table 1. Various Specialists, Type of, and & \\
\hline & Usage of Digital Radiography & \\
\hline
\end{tabular}

\begin{tabular}{|ccc|}
\hline Question & Answer & Response \\
& A. Expensive & $124(62 \%)$ \\
Reason for not Using & B. Poor image quality & $12(6 \%)$ \\
Digital Radiographs & D. Difficult to perform & $16(8 \%)$ \\
& E. No nearby Centres & $34(17 \%)$ \\
& F. All of the above & $4(2 \%)$ \\
& A. Radiation dose is reduced & $6(3 \%)$ \\
Reason for Using Digital & C. Immediate assessment of images & $24(12 \%)$ \\
Radiographs & D. Ease of image storage & $54(32 \%)$ \\
& E. Images can be adjusted & $32(16 \%)$ \\
& F. All of the above & $22(11 \%)$ \\
\hline Table 2. Reasons for Preference of Digital Radiography
\end{tabular}

\begin{tabular}{|ccc|}
\hline Question & Answer & Response \\
Frequent Use of Digital & A. Often & $130(65 \%)$ \\
Radiographs & B. Very Often & $46(23 \%)$ \\
Frequent Use of Conventional & C. Rare & $24(12 \%)$ \\
Radiographs & A. Often & $96(48 \%)$ \\
Satisfaction with Digital & B. Very Often & $56(28 \%)$ \\
Radiography & C. Rare & $48(24 \%)$ \\
& A. Satisfied & $144(72 \%)$ \\
Preference for Diagnostic Quality & B. Neutral & $48(24 \%)$ \\
& C. Unsatisfied & $8(4 \%)$ \\
Patient Preference & B. Conventional & $180(90 \%)$ \\
Radiation Protection is Used by & Radiography & $20(10 \%)$ \\
the Operator? & A. Digital Radiography & $152(76 \%)$ \\
& A. Conventional Radiograph & $48(24 \%)$ \\
Patient uses radiation protection? & A. Yes & $102(51 \%)$ \\
\cline { 2 - 4 } & B. No & $98(49 \%)$ \\
\hline Table 3. Responses for Frequency, Satisfaction, and \\
Radiation Protection of the Practitioners
\end{tabular}

\section{DISCUSSION}

Radiographs are widely used in dentistry to enhance the management of the patient. It is an essential diagnostic tool in dentistry and key determinants of appropriate diagnosis. In dental practice, digital radiography is slowly becoming an irreplaceable part. A preference for digital vs. conventional radiographs is increasing among dentists with technological advances. ${ }^{10,11}$

The principal aim of the present study was to evaluate the extent of interest in digital radiography and conventional radiographs among dental practitioners. In our study, $65 \%$ of them answered that they use digital radiographs often and 48 $\%$ use conventional radiographs often, $80 \%$ of them answered that their diagnostic quality is improved by using digital radiographs. Dolekoglu et al. ${ }^{12}$ reported that $67 \%$ of Turkish dentists used digital radiography. According to Lee et al. ${ }^{13}$ digital sensors were used by $77.2 \%$ of the Korean dentists. Still, digital radiography is yet to reach extensively in Indian dental practitioners compared to developed countries.

Several other studies evaluating dentists' attitudes towards digital radiography reported different reasons for the popularity such as time efficiency, absence of a need to develop images, ease of image storage, and reduced radiation ${ }^{14}$, as compared to our study results. We found that digital radiography may be of crucial value for dental practitioners as it allows rapid decision making for optimal diagnosis and treatment plans.

$90 \%$ of the practitioners believe that digital radiography increases their diagnostic ability. Similar to our result, most of the studies have accomplished that the diagnostic value of digital images is improved than that of conventional radiographs. ${ }^{15}$

Non-availability and cost of equipment were the major reasons cited for non-use of digital techniques, in accord with previous studies such as Brian et al, ${ }^{10,16}$ as similar to our study $62 \%$ of practitioners do not use digital radiographs as they are expensive, $6 \%$ because of poor image quality, $17 \%$ because of no nearby centres for digital radiography, difficulty in operating systems $5 \%$.

The major disadvantages of digital radiography include reduced spatial resolution, and limited sensor size and flexibility, however $72 \%$ of our sample indicated satisfaction with the currently available techniques, which is more than the proportion reported by Reddy et al. ${ }^{14}$

In our study, $51 \%$ of the practitioners used radiation protection, whereas Chaudhry et al ${ }^{17}$ observed that $31 \%$ of dentists in the national capital region use the lead apron while taking the radiography. Yet most of these studies showed the neglect of radiation safety by dental practitioners. In the present study although more than $50 \%$ uses radiation safety only $39 \%$ of their patients used radiation protection during exposure. Hintze et $\mathrm{al}^{18}$ showed that there was reduction in exposure for digital imaging up to $25 \%$, which was statistically significant with phosphor plate systems.

Digital radiography practices are more common in developing centres with heavy population and the contemporary technologies are essential. Thus, this necessitates the need of advanced training for practitioners and also enhanced digital services in these developing centers. It can be inferred from the study that there is lack of 
knowledge in regard to radiation protection protocols and radiation hazards itself and also the major reason for not using digital radiography is because of its cost factor. The need for availability of standard improved quality of care equally raises the point for cost effective methods for the developing technologies.

This study had some limitations where the number of respondents could not be controlled. Moreover, the number of respondents varied among specialties, working sectors and not equally distributed.

\section{CONCLUSIONS}

Although the film system had better resolution than the digital imaging systems, it was not proven to be clinically important. With developing modern technologies, there continues improvisation of image quality in digital systems at lower radiation doses. Digital radiographs are expensive, difficult to access, require less equipment for film storage, and require less manpower. Templating of images is easy in digital radiography, as the images are comparable to anatomical size. Though many still use conventional radiographs, the future is digital radiographs. Better detectors, faster image processing, bigger and sharper displays will transform the diagnostic imaging modality. Virtual displays may play a role in future diagnostic imaging. Though the world is rapidly digitalizing in various fields, the need for digital radiographic growth is mandatory in all parts of the country irrespective of the population and settlements in India. The need for diagnostic and treatment standardizing is a growing necessity for balanced health care.

Data sharing statement provided by the authors is available with the full text of this article at jemds.com.

Financial or other competing interests: None.

Disclosure forms provided by the authors are available with the full text of this article at jemds.com.

\section{REFERENCES}

[1] Peers A, Hill FJ, Mitropoulos CM, et al. Validity and reproducibility of clinical examination, fibre-optic transillumination, and bite-wing radiology for the diagnosis of small approximal carious lesions: an in vitro study. Caries Res 1993;27(4):307-11.

[2] Jacobsen JH, Hansen B, Wenzel A, et al. Relationship between histological and radiographic caries lesion depth measured in images from four digital radiography systems. Caries Res 2004;38(1):34-8.
[3] Wenzel A. Current trends in radiographic caries imaging. Oral Surg Oral Med Oral Pathol Oral Radiol Endod 1995;80(5):527-39.

[4] Haak R, Wicht MJ, Noack MJ. Conventional, digital and contrast-enhanced bitewing radiographs in the decision to restore approximal carious lesions. Caries Res 2001;35(3):193-9.

[5] Pai SS, Zimmerman JL. Digital radiographic imaging in dental practice. Dent Today 2002;21(6):56-61.

[6] Gart C, Zamanian K. Global trends in dental imaging: the rise of digital. Dental Tribune July 27, 2010.

[7] Berkhout WER, Sanderink GCH, Van der Stelt PF. A comparison of digital and film radiography in Dutch dental practices assessed by questionnaire. Dentomaxillofac Radiol 2002;31(2):93-9.

[8] Wakoh M, Kuroyanagi K. Digital imaging modalities for dental practice. Bull Tokyo Dent Coll 2001;42(1):1-14.

[9] Briggs-Kamara M, Okoye PC, Omubo-Pepple VB. Radiation safety awareness among patients and radiographers in three hospitals in Port Harcourt. Am J Sci Ind Res 2013;4(1):83-8.

[10] Brian JN, Williamson GF. Digital radiography in dentistry: a survey of Indiana dentists. Dentomaxillofac Radiol 2007;36(1):18-23.

[11] Hellén-Halme K. Quality aspects of digital radiography in general dental practice. Swed Dent J Suppl 2007;(184):960.

[12] Dölekoğlu S, Fișekçioğlu E, İlgüy $M$, et al. The usage of digital radiography and cone beam computed tomography among Turkish dentists. Dentomaxillofac Radiol 2011;40(6):379-84.

[13] Lee BD, Ludlow JB. Attitude of the Korean dentists towards radiation safety and selection criteria. Imaging Sci Dent 2013;43(3):179-84.

[14] Reddy RS, Ramesh R, Kiran CS, et al. Knowledge and attitude of dental fraternity towards cone beam computed tomography in south India - a questionnaire study. Indian Journal of Dentistry 2013;4(2):88-94.

[15] İlgüy D, İlgüy $M$, Dinçer $S$, et al. Survey of dental radiological practice in Turkey. Dentomaxillofacial Radiol 2005;34(4):222-7.

[16] Wenzel A, Møystad A. Decision criteria and characteristics of Norwegian general dental practitioners selecting digital radiography. Dentomaxillofac Radiol 2001;30(4):197-202.

[17] Chaudhry M, Jayaprakash K, Shivalingesh KK, et al. Oral adiology safety standards adopted by the general dentists practicing in National Capital Region (NCR). J Clin Diagn Res 2016;10(1):ZC42-5.

[18] Hintze H, Wenzel A, Frydenberg M. Accuracy of caries detection with four storage phosphor systems and Espeed radiographs. Dentomaxillofac Radiol 2002;31(3):170-5. 